\title{
1 Regulatory T cell therapy: Current and future design perspectives
}

2 Jyoti Rana and Moanaro Biswas*

3 Herman B Wells Center for Pediatric Research, Department of Pediatrics, Indiana 4 University School of Medicine, Indianapolis, IN, USA

5

6

*Correspondence:

7 nbiswas@iu.edu

8

9 Keywords: Regulatory $T$ cells, Immune tolerance, autoimmune diseases, antigen specific T cells, Transgenic TCR, scFv, Chimeric antigen receptor,

\section{Abstract}

13 Regulatory $T$ cells (Tregs) maintain immune equilibrium by suppressing immune 14 responses through various multistep contact dependent and independent 15 mechanisms. Cellular therapy using polyclonal Tregs in transplantation and 16 autoimmune diseases has shown promise in preclinical models and clinical trials. 17 Although novel approaches have been developed to improve specificity and efficacy 18 of antigen specific Treg based therapies, widespread application is currently restricted. 19 To date, design-based approaches to improve the potency and persistence of 20 engineered chimeric antigen receptor (CAR) Tregs are limited. Here, we describe 21 currently available Treg based therapies, their advantages and limitations for 22 implementation in clinical studies. We also examine various strategies for improving 23 CAR T cell design that can potentially be applied to CAR Tregs, such as identifying 24 co-stimulatory signalling domains that enhance suppressive ability, determining 25 optimal scFv affinity/avidity, and co-expression of accessory molecules. Finally, we 26 discuss the importance of tailoring CAR Treg design to suit the individual disease.

This is the author's manuscript of the article published in final edited form as: 


\section{Highlights:}

- The tolerogenic effect of Tregs can be effectively harnessed for cellular therapy

- Limitations of polyclonal Treg therapy led to the generation of engineered Tregs

- CAR Tregs confer antigen specificity without requirement for MHC restriction

- CAR Treg design is currently based on $2^{\text {nd }}$ generation CAR T cells for cancer therapy

- Developments to improve potency of CAR T cells for cancer may be applied to Tregs 


\section{Introduction}

\subsection{Phenotype}

31 Regulatory $T$ cells (Tregs) are a dynamic and specialized subset of $C D 4^{+} T$ cells which play an indispensable role in the suppression of exacerbated immune responses, maintenance of peripheral tolerance and tissue integrity [1]. Tregs are characterized by the expression of high levels of the IL-2 receptor $\alpha$-chain CD25, and the lineage specific transcription factor forkhead box protein 3 (FoxP3). The suppressive function of Tregs relies heavily on high and stable expression of FoxP3, which together with other transcription factors, determines the functional program of Tregs by inducing expression of specific genes and epigenetic signature during their development [2-4]. Constitutive stable expression of FoxP3 is considered indispensable for lineage maintenance as the ablation of Foxp3 from mature Tregs leads to loss of function and conversion to other T helper (Th) cell types [5].

\subsection{Classification}

43 Two broad categories of Tregs have been described according to the site of origin: 44 central, naturally occurring or thymus derived Tregs (tTreg) and peripheral Tregs (pTreg) [6]. In the thymus, tTregs are selected positively through MHC-II dependent T cell receptor (TCR) interactions, resulting in a relatively high avidity selection [7]. On the contrary, pTregs originate from conventional $C D 4^{+} T$ cells $\left(T_{\text {conv }}\right)$, usually in the presence of TGF- $\beta$ and IL-2 [7]. Together, both these types of Tregs play specialized roles in controlling both innate and acquired immune responses to self and foreign antigen. After development, maintenance of functional stability and homeostatic proliferation requires continuous signaling in Tregs $[8,9]$. The interaction of cognate antigen with TCR initiates activation of Tregs. However, complete activation requires a secondary signal which is provided by co-stimulatory molecules like CD28, ICOS and/or CD40 [10-12]. In the presence of the TCR signal alone, both $T_{\text {conv }}$ and Tregs undergo a state of anergy and unresponsiveness. A broad spectrum of co-stimulatory and co-inhibitory receptors and their ligands are engaged in activation during TCR

57 dependent Treg activation [13, 14]. 


\subsection{Immune suppressive function}

In a healthy individual, Tregs accumulate in non-lymphoid organs and barrier tissues such as skin, lung and the gastrointestinal tract [15-18]. During an inflammatory response, Tregs migrate from the inflamed tissue to draining lymph nodes and exert immune suppression not only at the site of inflammation but also in local secondary lymphoid tissues [19-21]. Tregs exert their immunosuppressive function by direct cellcontact dependent or independent mechanisms (Figure 1). Some of these mechanisms for modulation of the immune response involve the secretion of inhibitory cytokines like TGF- $\beta$, IL-10 and IL-35 [22-26], consumption of IL-2 [27-30], production of lytic proteins such as granzyme and perforin [31,32], and modification of APCs by down-regulation or trogocytosis of peptide-MHC II, CD80 and CD86 [33-35]. Besides these mechanisms, antigen specificity also plays an important role in Treg mediated suppression through physical co-clustering of TCR stimulated Tregs with IL-2 producing auto-reactive $T$ cells in lymph nodes to suppress autoimmunity in a negative feedback manner [36].

Over the years, research on Treg biology has undergone significant advances. Accumulated evidence demonstrates that Treg play an essential role in the control of a variety of physiological and pathological immune responses, including anti-microbial and anti-tumor responses and transplant immunity [37-39]. In this review, we examine the different types of Treg based therapies currently being tested, as well as introduce various strategies for improving CAR T cell design that can potentially be applied to CAR Tregs to improve function, persistence, and efficacy.

\section{Role of Tregs}

\subsection{Sentinel for $T$ cells that escape thymic selection}

82 In general, Tregs constitute only 1 to $2 \%$ of peripheral blood lymphocytes (PBL).

83 Perturbations in Treg numbers often results in the pathology of many common autoimmune diseases [40], whereas loss of function gene mutations in the Foxp3 gene leads to the development of a range of autoimmune and inflammatory disorders known as immunodysregulation, polyendocrinopathy, enteropathy, X-linked syndrome (IPEX) $[41,42]$. Several studies in different autoimmune disease models have indicated an association of disease phenotype mainly with Treg function rather than defective Treg numbers in patients. In multiple sclerosis [43], type I diabetes [44], psoriasis [45] and 
myasthenia gravis [46], peripheral blood Tregs were found to have reduced capacity to suppress $\mathrm{T}$ cell proliferation and interferon gamma (IFN- $\mathrm{\gamma}$ ) production. Recent evidence in patients with allergic or asthmatic disease suggested decreased frequency of IL-10 secreting Tregs in comparison to healthy individuals [47, 48].

\subsection{Dampen and curtail inflammatory responses}

Although Tregs can effectively regulate $T_{\text {conv }}$ cells under normal circumstances, certain conditions like infection require robust effector function. Tregs play an important role in controlling the balance between induction of a proinflammatory anti-pathogen response and an anti-inflammatory response to prevent damage to host cells. For example, in virus induced encephalitis, and in lung inflammation following influenza $A$ infection, Tregs were found to reduce disease severity by suppressing the overactivation of the immune response $[49,50]$. This balance can be destabilized following the sensing of specific local proinflammatory signals like IL-6 and IFN- $\gamma$, which causes Tregs to lose their suppressive phenotype [51, 52]. The role of Tregs in chronic viral infections is not completely understood to date. In patients with hepatitis B and hepatitis $C$ virus infection, an increase in the number of peripheral Tregs have been reported which prevents effective antiviral immunity [53-55].

\section{$107 \quad 2.3$ Tregs in the tumor microenvironment}

108 In contrast to infection, within the tumor microenvironment, the dominant suppression of Tregs over $T_{\text {conv }}$ becomes exaggerated and pathological. Increased activity of Tregs protects tumor tissues from immune surveillance and hence recognition. In patients with different cancer types e.g. lung, pancreatic, breast, liver and skin, an increased proportion of Tregs have been reported, which inhibits proliferation and IFNy production by $\mathrm{T}_{\text {conv }}$ and NK cell mediated cytotoxicity [56-60]. Studies performed in murine tumor models have demonstrated that ablation of Tregs triggers a rapid, spontaneous immune response against the tumor tissue and improves the effectiveness of anti-cancer immunotherapy [61-63].

\section{3. Sources of Tregs for cell therapy}

118 The importance of Tregs in inducing both in vivo and ex vivo tolerance underscores 119 their immense potential as a therapeutic tool. Of these, the use of cellular Treg based 120 therapies has shown promising outcomes in both pre-clinical studies as well as in the 121 clinic. 


\section{$\underline{3.1 \text { In vivo induction of antigen specific Tregs }}$}

$123 \mathrm{CD}^{+} \mathrm{T}_{\text {conv }}$ cells can develop into Tregs depending on a mixture of contact dependent 124 and cytokine signals present during antigen presentation by professional APCs. For 125 example, repetitive stimulation of naive T cells with antigen presenting immature DCs 126 leads to the induction of IL-10 producing Tregs [64]. Animal models of autoimmune 127 and allergic diseases have provided evidence for the induction of IL-10 producing 128 Tregs following peptide administration [65-67]. However, in the non-obese diabetic 129 (NOD) mouse model and in multiple sclerosis patients, administration of self or altered 130 peptides resulted in severe inflammatory or anaphylactic side effects [68, 69].

131 For induction of Tregs, use of monoclonal antibodies (mAbs) has shown significant 132 outcomes. Studies in the NOD mouse model reported that anti-CD3 treatment can induce immunoregulatory mechanism by selectively depleting pathogenic cells and inducing TGF- $\beta$ secreting Tregs [70, 71]. In patients with early onset of type I diabetes, anti-CD3 monoclonal antibody treatment resulted in maintenance of residual beta cell function and required administration of lower insulin doses [72, 73]. A phase 2 clinical trial of teplizumab (an Fc receptor-nonbinding anti-CD3 monoclonal antibody) administered to relatives of diabetes I patients showed delayed progression of the disease [74]. This therapy has also been tested in other animal models of autoimmunity, multiple sclerosis [75, 76], colitis [77], rheumatoid arthritis [78] and transplantation [79]. Another candidate for mAb based approach to induce Treg is antiCD45RO/RB which was shown to induce anergic and suppressive human antigen specific $\mathrm{CD}^{+}$and $\mathrm{CD}^{+} \mathrm{T}$ cells upon stimulation in vitro [80]. A recent preclinical study has demonstrated the potential of anti-CD45RC mAb administration in the prevention of allograft rejection and graft versus host disease (GvHD) inhibition [81].

146 Other approaches to induce and expand Tregs in vivo involve the use of the 147 immunosuppressive drug rapamycin [82], administration of low dose IL-2 [83, 84], IL148 2/IL-2 antibody complex [85-87], use of Tumor necrosis factor receptor 2 (TNFR2) 149 blockers [88, 89]. All these strategies have been used in several clinical trials either 150 individually or in combination with polyclonal Tregs.

\subsection{Ex vivo expanded polyclonal Tregs}

152 The clinical application of polyclonal Tregs is considered a next generation cellular 153 therapy for several autoimmune diseases and inflammatory immune disorders. Tregs 
154 isolated from peripheral blood are stimulated and expanded in vitro using anti155 CD3/CD28 antibody coated beads and high dose IL-2 [90, 91]. Expanded Tregs retain 156 expression of cell specific genes and are reportedly more efficient in suppressive 157 function [92]. Another approach for the preferential expansion of Tregs over other $T$ 158 cell subsets involves the use of anti CD28 superagonists, with reportedly high Treg 159 stability [93].

\subsubsection{Thymic derived, natural Tregs}

161 The first preclinical proof of concept for use of polyclonal Tregs was demonstrated in 1621995 by Sakaguchi and co-workers, who demonstrated that $C D 4{ }^{+} C D 25^{+} T$ cells could 163 be used to transfer tolerance in athymic nude mice by suppressing self-reactive 164 lymphocytes [94]. Since then, approaches that involve boosting Treg to $T_{c o n v}$ ratios 165 have been tested in several disease settings. Tregs with a polyclonal specificity have 166 demonstrated potential in various preclinical models of GvHD [95-97], solid organ transplantation [98, 99] and autoimmune diseases [96, 100, 101]. Several clinical trials examining the safety and feasibility of polyclonal Tregs for type I diabetes [102, 103], transplantation [104] and GvHD [105-107] have been carried out, demonstrating their efficacy in immunotherapy (Table 1). Some other clinical trials for polyclonal treg therapy in autoimmune hepatitis (NCT02704338), Crohn's disease (NCT03185000), Pemphigus (NCT03239470) and Alzheimer's disease (NCT03865017) are also under investigation. Beside autoimmune diseases, the use of polyclonal Tregs in other disease models have also shown significant therapeutic potential. In non-immune diseases like cardiovascular disease, obesity, type 2 diabetes and degenerative diseases, administration of polyclonal Tregs are reported to reduce the inflammation and morbidity rate by contributing to tissue homeostasis and repair [108, 109]. In genetic disorders, characterized by mutations or defect in production of an essential protein, such as for clotting factor VIII or IX in hemophilia, lack of tolerance to protein replacement therapy is often observed. In this case, adoptive transfer of polyclonal Tregs effectively suppressed immune responses to therapeutic proteins in preclinical animal studies [110, 111]. Polyclonal Treg cell therapy is therefore generally considered safe and efficacious, although obtaining sufficient cell numbers can be challenging in many disease scenarios $[112,113]$.

While results from preclinical and Phase $\mathrm{I} / \mathrm{II}$ clinical studies demonstrating the safety and feasibility of Treg infusion therapy are encouraging, outcomes from Phase III 
studies will truly indicate whether polyclonal Treg therapy will become a common standard of care in the treatment of different autoimmune diseases, transplant rejection and GvHD.

\section{$190 \quad 3.2 .2$ FoxP3 transduced T cells}

191 There are a few approaches for circumventing the requirement of large polyclonal Treg cell numbers for therapy. Tregs constitutively express the transcription factor FoxP3, which is critical for their immunosuppressive function. Several groups have shown that ectopic expression of FoxP3 can confer a suppressive phenotype to naive or memory CD4 ${ }^{+} T$ cells $[4,114]$. In a mouse model with recent onset of type I diabetes, a single injection of $10^{5}$ FoxP3 transduced islet specific $T$ cells was reported to stabilize and reverse the disease condition [115]. Lentiviral delivery of FoxP3 gene into IPEX patient-derived $\mathrm{CD}^{+}{ }^{+} \mathrm{T}$ cells mirrored Treg population from healthy donors, with characteristic features like decreased proliferation, hyporesponsiveness, reduced cytokine release and suppressive activity [116]. These induced Tregs were demonstrated to be stable in inflammatory conditions not only in vitro but also in vivo in a xenograft mouse model of GvHD [116]. Forced expression of FoxP3 in CD4+ T cells isolated from FVIII immunized mice generated antigen specific suppressor Treg like cells, that conferred long lasting prevention of inhibitory immune response against FVIII replacement therapy [117]. Several other studies have shown the efficiency of FoxP3 transduced Tregs in combating autoimmune diseases like allergy [118], renal injury [119] and collagen induced arthritis [120]. Recently, Honaker and co-authors demonstrated the use of the CRISPR/Cas9 system for stable and high-level expression of FoxP3 in Tconv cells. These edited Treg like cells were able to suppress the immune response in a xeno-GvHD mouse model [121]. Further, CRISPR based gene correction for regulated expression of FoxP3 demonstrated that gene editing in IPEX can preserve HSPC differentiation potential and edited regulatory and effector $T$ cells restored their regulatory phenotype and function [122]. These studies demonstrate applicability of gene correction in the treatment of autoimmune diseases.

215 Another approach which has been used to enforce Treg differentiation involves use of 216 the cell permeable form of FoxP3, linked to the protein transduction domain (PTD) 217 from the HIV transactivator of transcription, which allows FoxP3 to be delivered to the 218 cytoplasm and nucleus. This protein form has been shown to induce a Treg phenotype 219 in both human and mouse $T$ cells $[123,124]$. Repeated infusion resulted in the 
220 amelioration of the scurfy phenotype, inflammatory bowel disease or rheumatoid 221 arthritis in preclinical animal models [125, 126]. However, a major limitation of this approach involves the high cost for human patients and also a requirement for further exploration in terms of immunosuppressive specificity and stability.

\section{$224 \quad 3.3$ TCR enrichment}

225 The major risk with polyclonal Treg therapy is off-target suppression of immune responses, which might lead to an increased susceptibility to opportunistic infections or suppression of anti-tumor activity [127]. Developing antigen specific Treg therapy therefore provides a more effective and safer approach. Several preclinical studies using ex vivo or in vivo expanded antigen (Ag) specific Tregs have shown improved potency and lower risk of pan-immunosuppression [128-133]. In vitro priming of Tregs with alloantigen can generate tailor made Tregs with appropriate antigen specificity. Jiang et al reported induction of human Tregs specific for human leukocyte antigen A2 (HLA A2) peptide (138-170 aa) through peptide pulsing of immature DCs. These Tregs efficiently suppressed Tconv cells in a cell contact dependent manner [134]. Studies performed in a type I diabetes mouse model demonstrated that pancreatic lymph node Tregs pulsed with islet antigen were significantly better in prevention and treatment of disease as compared to polyclonal Tregs [131-133]. Similar results were obtained in a skin allograft and GvHD mouse model, suggesting the improved efficacy of antigen specific Tregs [128-130]. Further, in a humanized mouse model for transplantation, antigen specific Tregs demonstrated better efficacy when used in much lower numbers as compared to polyclonal Tregs $[135,136]$. In a recent study, Tregs isolated from

242 FVIII sensitized mice, expanded in vitro with FVIII, antigen presenting cells and IL2 were found to suppress anti-FVIII antibody response and induce long term tolerance

244 to FVIII [137]. Overall, these studies demonstrate the potential of antigen specific 245 Tregs in transplant rejection, autoimmunity and recombinant protein therapies.

\section{$246 \quad 3.4$ Antigen specific engineered Tregs}

247 Regardless of the improved outcome from TCR enriched antigen specific Tregs, the 248 main limitation of this approach are complex cell culture requirements, and a low 249 starting population of antigen specific Tregs, especially in genetic disorders with large 250 mutations that result in a lack of protein expression like hemophilia, Pompe and 251 Fabry's disease [138-141]. To overcome these limitations, engineered Tregs 
expressing antigen specific transgenic TCRs or synthetic chimeric antigen receptors are an alternative approach to induce targeted immunosuppression.

\section{$254 \quad$ 3.4.1 TCR transgenic Tregs}

255 The first proof of concept for the use of T cells over-expressing the alpha ( $\alpha$ ) and beta

256 ( $\beta$ ) chains of antigen specific TCRs was obtained in the field of cancer immunotherapy 257 [142]. This approach was later applied to redirect Treg specificity towards target antigens involved in autoimmune diseases. Several preclinical studies in mouse models have shown that TCR engineered Tregs are more efficient in suppression of effector responses against specific antigens in colitis, multiple sclerosis, arthritis and autoimmune diseases [143-146]. Further, in vitro expanded Tregs with direct alloantigen specificity conferred by transgenic TCR were more efficient in tolerance induction to MHC mismatched heart grafts [147].

264 The success achieved in mouse Tregs encouraged the development of human TCR 265 transgenic Tregs. Kim and co-workers showed that TCR transduced Tregs recognizing 266 a HLA class II restricted peptide to the C2 domain of FVIII were able to suppress both 267 T and B cell responses against FVIII in HLA transgenic hemophilia A mice [148]. Hull and colleagues demonstrated the efficacy of lentiviral mediated islet antigen specific TCR transfer in human Tregs in the prevention of diabetes [149]. In a recent study, single cell TCR analyses of islet Tregs revealed their specificity for insulin and other islet derived antigen and these antigen specific Tregs were reported to be efficient in protecting NOD mice from diabetes [150].

273 There are some limitations of this approach such as the requirement for MHC 274 restriction and risk of mispairing with endogenous TCR, although this can be 275 addressed by introducing disulphide links or knocking out the endogenous $\alpha \beta$ TCR. A 276 major concern is that the majority of these transgenic Tregs were generated using 277 TCRs isolated from $T_{\text {conv }}$ cells and it is highly likely that the intrinsic affinity and specificity of TCRs isolated from Tregs are distinct from $T_{\text {conv, }}$ which can affect the stability of engineered Tregs, avidity and migration to specific niches.

\subsubsection{Chimeric antigen receptor (CAR) Tregs}

281 Engineering antigen specific $T$ cells through the incorporation of chimeric antigen receptors (CARs) has found unprecedented success in the treatment of hematologic malignancies [151, 152]. The synthetic CAR molecule, comprised of an extracellular 
antigen binding domain from a monoclonal antibody and intracellular $\mathrm{T}$ cell signaling domains [153] can identify the target antigen in an MHC independent manner without the requirement for antigen presentation, thus overcoming the limitations posed on TCR transgenic Tregs.

288 Building on the success of $2^{\text {nd }}$ generation CARs in cancer treatment, to date, all CAR 289 Treg studies have used an identical design that includes a single co-stimulatory 290 domain linked to the primary $\mathrm{CD} 3 \zeta$ signaling domain. Almost a decade ago, initial 291 preclinical studies with second generation CAR Tregs were performed in mouse 292 models of colitis and xeno-transplantation [154, 155] and the first human CAR Tregs 293 were generated [156]. Since then several studies on CAR Tregs have showed 294 improved efficacy, enhanced persistence and stability in different disease models like 295 colitis [143, 155, 157], GvHD [158-161] and skin rejection [162]. The possible 296 mechanisms by which CAR Tregs may induce immunosuppression are represented 297 in Figure 2.

298 In recent years, CAR Treg technology has been applied to induce immune 299 suppression against soluble antigens. In a hemophilia A model, human Tregs 300 expressing FVIII specific CAR Tregs were able to suppress the proliferation of FVIII 301 specific $T_{\text {conv }}$ cells $[148,163]$. Tregs possess a unique feature of bystander 302 suppression which enables rational design to target Treg cells to the inflamed tissue, 303 without necessarily targeting cell surface antigens. Taking advantage of this property, 304 a CAR molecule was developed targeting citrullinated vimentin (CV), which is present 305 abundantly and exclusively in extracellular matrix of inflamed joints in rheumatoid 306 arthritis (RA) patients [164]. These cells were able to proliferate in the presence of synovial fluid from RA patients, suggesting that presence of CV in inflamed joints is sufficient to activate these CAR Tregs. This approach can prove beneficial in certain inflammatory settings as direct targeting of antigen expressing cells may be 310 detrimental due to the reported cytolytic activity of CAR Tregs in certain cases [165]. 311 In a recent study, CAR Tregs designed against insulin were found to be functionally 312 stable and suppressive in in vitro experiments and persisted in vivo, but were unable 313 to prevent spontaneous diabetes in NOD/Ltj female mice model [166].

314 B cell targeting antibody receptor (BAR) Tregs, which comprises an extracellular 315 antigen domain (rather than the ScFv of a CAR), complexed to primary and co- 
316 stimulatory signaling molecules, is another strategy which has recently been used to

317 demonstrate suppression of FVIII specific B cells both in vitro and in a hemophilia A 318 mouse model $[167,168]$. This approach provides promising results in these initial 319 studies and require further studies using different disease models.

\section{4. Considerations for CAR Treg design}

321 CARs have opened up avenues to engineer Tregs against a wide variety of antigens. 322 However, there are several aspects of CAR design which can be improved upon with 323 context to Treg engineering. One of the major issues in the Treg based cellular therapy 324 is the stability and plasticity of their phenotype. Tregs demonstrate plastic 325 differentiation depending on the TCR signal strength which determines the binding of 326 FoxP3 to a set of regulatory factors [169, 170], and the microenvironment which can 327 affect the post-translational modification of FoxP3 [171]. In an inflammatory 328 environment or due to the strong signals, Tregs can exhibit features of Th cells, such 329 as the secretion of pro-inflammatory cytokines and the expression of Th specific 330 transcription factors, but also still maintain the expression of Foxp3 [172, 173]. Thus, 331 tailoring CAR Treg design according on the disease model is critical. Another 332 important factor in adoptive cellular therapy is the potential for a transient suppressive 333 effect due to short lived persistence. Natural Tregs exhibit the phenomenon of 334 Infectious tolerance i.e. conversion of $T_{\text {conv }}$ cells into Tregs by a small number of 335 antigen specific Tregs, thus generating long-lived antigen specific tolerance [174, 175]. 336 The exact molecular mechanism of this phenomenon is not known yet but studies have 337 shown that secretion of cytokines like TGF- $\beta[176,177]$, catabolism of tryptophan [176, 338 178] and interaction with DCs through co-inhibitory molecules like CTLA4 and PD1 339 [179] play an important role. With CAR Tregs, it is not known if these cells can induce 340 infectious tolerance, more importantly in case of soluble antigens where contact 341 dependent suppression might not occur. In these circumstances, it might be important 342 to consider multiple infusions in order to extend tolerance. These different aspects of 343 Treg behaviour should be taken into consideration while designing antigen specific 344 Tregs for therapeutic purposes. In this section, we describe some of the modular 345 346 design approaches which can be utilized to achieve the full potential of these therapies. 


\subsection{Costimulatory molecules}

348 Extensive research has been carried out on the function of different co-stimulatory 349 molecules to optimize the efficacy of $T_{\text {conv }}$ cell-based CAR therapies for oncology. 350 Currently, the most commonly used costimulatory molecules in CAR $\mathrm{T}_{\text {conv }}$ therapy are 351 CD28 and 4-1BB [180] (Figure 3A). Although both molecules have proved to be 352 remarkably effective in enhancing CAR therapy, they have exhibited very dissimilar 353 kinetics, persistence and toxicity profile in patients [181-183]. Other groups have 354 studied the functional effect of CARs expressing other co-stimulatory domains like 355 ICOS or OX-40. The use of ICOS based CARs resulted in a greater propensity towards 356 TH1/TH17 polarization and increased secretion of Th17 associated cytokines, with enhanced persistence in a xenograft tumor model $[184,185]$. Addition of the OX40 endodomain led to reduced secretion of IL-10 by $\mathrm{T}_{\text {conv }}$ cells without altering the expression of other proinflammatory cytokines [186]. In a different approach, inhibitory CARs expressing PD1 or CTLA4 when used together with CD28 or 4-1BB CARs, limited toxicity by restricting off-target $\mathrm{T}$ cell stimulation [187].

Like $T_{\text {conv }}$ cells, Tregs express a number of co-signaling molecules, which can both positively and negatively control Treg differentiation and function. But unlike $\mathrm{T}_{\text {conv }}$ CARs, fewer studies have been undertaken to investigate the impact of different cosignaling molecules on CAR Tregs. CD28 costimulation is essential for optimal Treg activation and function $[188,189]$ and hence used in the majority of CAR Tregs. Tregs expressing CD28 CAR were able to induce immune tolerance but did not persist for more than 3 weeks in the NOD/SCID gamma (NSG) mouse model [158]. 4-1BB TNF receptor expressing $2^{\text {nd }}$ generation CAR $T_{\text {conv }}$ cells have shown improved persistence and reduced exhaustion in tumors [190]. In a mouse model for preventing transplant rejection, a comparison of CAR Tregs expressing either CD28 or 4-1BB costimulatory signaling domains indicated that incorporation of the CD28 costimulatory molecule effectively inhibited graft rejection, while 4-1BB did not [191]. The role of 4-1BB in Treg

374 activation and function is not completely understood. A few reports have shown 375 involvement of 4-1BB in the improvement of Treg expansion and suppression [192376 194] while others have reported inhibition of suppressive function [195-197], thus meriting further study. However, understanding the importance of other co-signaling 378 molecules in maintaining CAR Treg suppressive functions will be critical for improving 379 their use in immunotherapy. 
380 For $T_{\text {conv }}$ CARs, a small subset of studies has been performed using $3^{\text {rd }}$ generation 381 CARs, in which a combination of co-signaling domains are used to further tailor $T$ cell 382 functionality. For example, combining CD28 and 4-1BB co-stimulatory domains 383 resulted in increased expression of type I interferon, greater expansion and improved 384 B-cell acute lymphoblastic leukemia regression in xenografts as compared to $2^{\text {nd }}$ 385 generation CARs [198]. Similarly, in a phase I dose escalation study, Ramos and co386 authors demonstrated the effectiveness of $3^{\text {rd }}$ generation CARs in the eradication of 387 minimal residual disease and more durable remissions [199]. In addition, incorporation 388 of the OX-40 domain resulted in reduced secretion of IFN-gamma and IL-2 with 389 reduced antitumor activity in vivo [200]. This strategy has not yet been tested in CAR 390 Tregs.

391 From a clinical perspective, it is critical to develop a CAR that maximizes the 392 suppressive property of Tregs while simultaneously inducing poor cytotoxicity or 393 proinflammatory cytokine responses if accidentally incorporated into a Tconv cell. 394 Therefore, there is a need to identify appropriate co-signaling domains that can 395 redirect CAR Tregs, while maintaining phenotype stability, cytokine production, 396 survival and persistence.

\section{$397 \quad 4.2$ Affinity and avidity tuning}

398 In comparison to the TCR, the antibody based CAR scFv has a much higher affinity 399 and avidity to the cognate antigen [201]. The impact of receptor affinity on determining 400 Treg signaling and suppressive function has been postulated, but not conclusively 401 reported. High levels of repeated signaling can lead to destabilization of the Treg 402 phenotype and hence a resultant loss of suppressive activity [52, 202]. In contrast, 403 signaling mediated by low amounts of a strong TCR agonist has been demonstrated 404 to increase the persistence of Tregs in vivo [203]. Depending on the disease model, 405 affinity of CAR molecules towards the target antigen can result in different outcomes.

406 In tumor therapy, the affinity of CAR molecule to the target antigen has been shown 407 to play an important role in the efficacy and persistence of these cells. Lowering the 408 scFv affinity towards target antigen has been shown to limit on-target, off-tumor 409 toxicities [204]. In a recent study, lower affinity CD19 CAR T cells showed increased 410 proliferation and cytotoxicity in vitro and enhanced anti-tumor activity and longer 411 persistence with decreased toxicities in vivo [205]. It is therefore expected that the use 
412 of moderate or low affinity CARs could have an impact on CAR Treg suppressive 413 function in vivo. Recently, Sprouse and co-workers conducted an extensive study to 414 demonstrate the role of high or low affinity TCR Tregs on the development of diabetes 415 in NOD TCR knockout mice. The results from this study reported that both low and 416 high affinity TCR Tregs use distinct non-redundant suppressive mechanisms for 417 combined effective control of tissue specific autoimmune response [206].

418 Besides affinity, overall receptor avidity may affect therapeutic outcome. Studies 419 performed with $\mathrm{T}_{\text {conv }}$ cells suggest that antigen specificity is not the only factor that 420 influences functional efficacy [207, 208]. In adoptive T cell based therapies for the 421 treatment of cancer or viral diseases, T cells expressing low avidity TCR showed a 422 reduced ability to respond to limited antigen concentrations together with an incapacity 423 to eliminate viral infections and tumors [207, 209, 210]. Further a skin allograft 424 rejection model demonstrated that TCR avidity is important for the optimal function of 425 Tregs [211]. Promoter usage and lentiviral transduction efficiency of T cells results in 426 heterogenous expression of the CAR molecule, making it hard to ensure consistent 427 behaviour among individual CAR T cells as avidities may vary. The integration of the 428 CAR construct into the endogenous TCR locus using CRISPR/Cas9 system limited 429 CAR expression in $\mathrm{T}_{\text {conv }}$ cells and has shown reduced tonic signaling and exhaustion. 430 The CRISPR edited CAR T cells demonstrated enhanced T cell potency as compared 431 to conventionally generated CAR T cells in a mouse model [212, 213]. Therefore, 432 finetuning CAR affinity and avidity is an attractive strategy that can be applied to Tregs 433 in order to modulate the outcome of CAR therapy.

\section{$434 \quad$ 4.3 Multi-antigen targeting}

435 In cancer, tumor relapse is the one of the major issues of CAR T cell therapy. To 436 overcome this problem, CAR T cells with specificity towards multiple tumor antigens 437 are being tested in preclinical models [214]. Approaches used to generate multi438 antigen CARs either involve co-administering CAR T cells with different antigen 439 specificities (pooled CARs), incorporating a single CAR molecule expressing two 440 distinct antigen binding domains in tandem (tandem CARs), or using a bi-directional 441 vector to co-transduce 2 CAR molecules with different specificities into a single cell 442 (Figure 3B). Pooled CARs, tandem CARs and dual antigen specific CARs has been 443 investigated in glioblastoma using human epidermal growth factor receptor-2 (HER444 2)/IL-13Ra2, B cell- Acute lymphoblastic leukaemia (B-ALL) using CD19/CD123 
445 specific CAR T cells [215, 216] and in other models [217-219]. The CARs were able 446 to generate a distinct response to each antigen, prevent antigen escape and improve 447 antitumor efficacy [219].

448 To date, multi-antigen specific CARs have not been used for Tregs. However, a study 449 on islet Tregs with multiple specificity for insulin as well as other islet derived antigens 450 protected against diabetes in NOD mice [150]. This suggests that a similar approach can be used to generate CAR Tregs with multiple specificities, to improve targeting.

\section{$452 \quad$ 4.4 Logic-gated CARs}

453 With the reported improvement in efficacy of dual antigen specific CAR T cells in tumor 454 models, several groups have now applied Boolean logics to further modulate the 455 outcome of these therapies (Figure 3C). Lanitis and co-authors proposed an AND 456 gate strategy to physically isolate the $\mathrm{CD} 3 \zeta$ signal from the co-stimulatory CD28 signal, 457 assembled into separate CAR moieties individually targeting mesothelin and a folate 458 receptor. These CAR T cells only transmit a signal upon encountering both antigens, 459 which results in highly selective antitumor efficacy [220]. AND gated CARs also exhibit 460 the natural biological properties of T cells, such as optimized proliferation, cytokine secretion, cytotoxicity, tumor-specific homing and off-tumor toxicity reduction [220]. 462 Recently, the AND logic gate strategy was combined with the Notch receptor system 463 where the binding of antigen to the first CAR triggers the SynNotch receptor to release 464 a transcriptional regulator, which regulates the expression of a second CAR molecule 465 [221]. Using this approach, it is possible to accomplish highly controlled signaling in 466 Tregs, which can overcome issues related to overstimulation and hence loss of 467 function.

468 Another interesting approach which has recently been utilized to overcome 469 immunosuppression in the tumor microenvironment of a pancreatic cancer model is 470 the generation of trivalent CAR T cells that respond only to tumor specific expression 471 patterns. Engineered T cells redirected to recognize the tumor specific prostate stem 472 cell antigen (PSCA) and cytokines TGF- $\beta$ and IL-4 transmitted individual signals 473 including antigen recognition, co-stimulation and cytokine secretion [222]. These three 474 signals led to activation, amplification and persistence of T cells, which resulted in safe 475 and selective lysis at tumor sites by CAR T cells. Generation of CAR Treg with a similar 476 strategy can improve the potency and long-term effectiveness of the therapy. For 
example, CAR Tregs recognising a specific antigen and immune enhancing cytokines such as IL6 and IFN-y could suppress inflammation driven by antigen specific $\mathrm{T}_{\text {conv }}$ cells.

\subsection{Co-expression and armored CARs}

481 The impact of accessory gene co-expression with CAR molecules in T cells is being 482 analyzed for tumor therapy. A tumor specific CD30 CAR in conjugation with chemokine receptor CCR4 resulted into enhanced tumor targeting by modulating the trafficking and homing to the tumor microenvironment [223]. Using a similar approach, in a B cell leukemia mouse model, CD28 $\zeta 2^{\text {nd }}$ generation CAR expressed with 4-1BB in trans induced more potent antitumor responses than $3^{\text {rd }}$ generation CAR and showed reduced exhaustion and increased persistence of CAR Tconv cells in vivo [198]. Besides these studies, several other groups have generated CAR T cells in association with molecules like CD80, CD40L or IL-15/inducible suicide gene (iCasp9) which has enhanced their functionality through multiple mechanisms [224-226]. Other modifications, such as armored CARs carrying a cytokine payload, are currently being tested [227-230]. In a study performed by Markley and Sadelain, use of CD19 CAR T cells constitutively expressing IL-2, IL-7, IL-15 or IL-21 showed improved antilymphoma activity in vivo than CARs without cytokines [231].

495 Translation of this approach for Tregs could involve constitutive co-expression of 496 inhibitory molecules like CTLA4 or PD1 that can help to improve the suppressive activity of Tregs in a contact dependent manner. CAR Tregs expressing immunosuppressive cytokines such as, IL-10, IL-35 or TGF- $\beta$ either constitutively or induced upon activation, have the potential to improve contact independent suppression. Importantly, these approaches will likely require optimization to tailor the function of Treg therapies to different diseases.

\section{Concluding remarks}

503 In the past decade, multiple studies have addressed the efficacy and potential of Treg based therapies. There are several formats of Tregs, from polyclonal to antigen specific, which are being used in clinical trials. CAR Tregs are a very promising approach but designs based on CAR $\mathrm{T}_{\text {conv }}$ cells for cancer may not be well suited for

507 preserving the immune suppressive function of Tregs. There are key differences in the 508 biology of Tregs and Tconv with respect to TCR stimulation, co-receptor ligation or 
509 cytokine production. Overall, further studies on the modular design of CARs and its 510 impact on Tregs in different disease models are required to establish a new generation 511 of cellular therapies.

\section{Acknowledgement}

513 Figures are created using Biorender.com.

\section{Conflict of Interest Statement}

515 The authors declare that the research was conducted in the absence of any conflict of 516 interest.

\section{Funding}

$518 \mathrm{MB}$ is in receipt of an early career investigator award from the Bayer Hemophilia 519 Awards Program (BHAP), and a career development award from the National 520 Hemophilia Foundation (NHF). 


\section{Figure Legends}

523 Figure 1: Mechanism of Treg suppression. Tregs are able to suppress immune

524 responses by direct and indirect mechanisms. Indirect mechanisms include the 525 production of anti-inflammatory cytokines like IL-10, IL-35 and TGF- $\beta$, which can 526 suppress $T_{\text {conv }}$ and NK cells. Release of perforin and granzyme can damage the target 527 cell membrane leading to apoptosis. Expression of CD39 and CD73 on Tregs mediate 528 conversion of ATP to adenosine and AMP causing reduced proliferation of $\mathrm{T}_{\text {conv }}$ cells. 529 Tregs have been observed to mediate a direct effect on $T_{\text {conv }}$ cells through receptor530 ligand interactions like PD1-PDL1, ICOS-ICOSL, TRAIL-DR5. By depriving IL2 from 531 the microenvironment, these cells reduce the proliferation of $T_{\text {conv }}$ and NK cells. 532 Interaction of Tregs with antigen presenting cells (APC) via CTLA4, PD1 and other co533 inhibitory molecules leads to direct APC suppression and indirect suppression of $\mathrm{T}_{\text {conv }}$ 534 cells.

535 Figure 2: Mechanism of CAR Treg mediated suppression. CAR Tregs can identify 536 either cell-surface or soluble antigen. Interaction of CAR Tregs with cells expressing 537 the target antigen on the cell surface activates the CAR Treg, which can secrete anti538 inflammatory cytokines, perforin and/or granzyme, or upregulate co-inhibitory 539 receptors like CTLA-4. CAR Tregs also upregulate CD25 which can indirectly 540 suppress $\mathrm{T}_{\text {conv }}$ cells by consumption of IL2. In the case of soluble antigen, CAR Tregs 541 can identify antigen bound non-specifically to the surface of APCs or to the antigen 542 specific $B$ cells receptor (BCR) on B cells, thus leading to initiation of both contact 543 dependent and independent suppression, although exact mechanisms remain to be 544 defined.

545 Figure 3: Next generation modifications of CAR constructs. A) Structure of $2^{\text {nd }}$ 546 and $3^{\text {rd }}$ generation CAR molecules. B) Different formats of multi-antigen specific 547 CARs. C) Representation of different forms of AND logic gated CAR cells. 


\section{References:}

550 1. Sakaguchi, S., Regulatory T cells: history and perspective. Methods Mol Biol, 2011. 707: p. 317.

2. Khattri, R., et al., An essential role for Scurfin in $C D 4+C D 25+T$ regulatory cells. Nat Immunol, 2003. 4(4): p. 337-42.

3. Hori, S., T. Takahashi, and S. Sakaguchi, Control of autoimmunity by naturally arising regulatory CD4+ T cells. Adv Immunol, 2003. 81: p. 331-71.

4. Fontenot, J.D., M.A. Gavin, and A.Y. Rudensky, Foxp3 programs the development and function of CD4+CD25+ regulatory T cells. Nat Immunol, 2003. 4(4): p. 330-6.

5. Sawant, D.V. and D.A. Vignali, Once a Treg, always a Treg? Immunol Rev, 2014. 259(1): p. 17391.

6. Abbas, A.K., et al., Regulatory $T$ cells: recommendations to simplify the nomenclature. Nat Immunol, 2013. 14(4): p. 307-8. 
24. Collison, L.W., et al., The inhibitory cytokine IL-35 contributes to regulatory T-cell function. Nature, 2007. 450(7169): p. 566-9.

25. Joetham, A., et al., Naturally occurring lung CD4(+)CD25(+) T cell regulation of airway allergic responses depends on IL-10 induction of TGF-beta. J Immunol, 2007. 178(3): p. 1433-42.

603

604

605

606

607

608

609

610

611

612

613

614

615

616

617

618

619

620

621

622

623

624

625

626

627

628

629

630

631

632

633

634

635

636

637

638

639

640

641

642

643

644

645

646

647

648

649

26. Rubtsov, Y.P., et al., Regulatory $T$ cell-derived interleukin-10 limits inflammation at environmental interfaces. Immunity, 2008. 28(4): p. 546-58.

27. Thornton, A.M. and E.M. Shevach, $C D 4+C D 25+$ immunoregulatory $T$ cells suppress polyclonal $T$ cell activation in vitro by inhibiting interleukin 2 production. J Exp Med, 1998. 188(2): p. 28796.

28. de la Rosa, M., et al., Interleukin-2 is essential for $C D 4+C D 25+$ regulatory $T$ cell function. Eur J Immunol, 2004. 34(9): p. 2480-8.

29. D'Cruz, L.M. and L. Klein, Development and function of agonist-induced CD25+Foxp3+ regulatory $T$ cells in the absence of interleukin 2 signaling. Nat Immunol, 2005. 6(11): p. 11529.

30. Pandiyan, P., et al., CD4+CD25+Foxp3+ regulatory $T$ cells induce cytokine deprivationmediated apoptosis of effector CD4+ T cells. Nat Immunol, 2007. 8(12): p. 1353-62.

31. Gondek, D.C., et al., Cutting edge: contact-mediated suppression by $C D 4+C D 25+$ regulatory cells involves a granzyme B-dependent, perforin-independent mechanism. J Immunol, 2005. 174(4): p. 1783-6.

32. Cao, X., et al., Granzyme B and perforin are important for regulatory $T$ cell-mediated suppression of tumor clearance. Immunity, 2007. 27(4): p. 635-46.

33. Akkaya, B., et al., Regulatory $T$ cells mediate specific suppression by depleting peptide-MHC class II from dendritic cells. Nat Immunol, 2019. 20(2): p. 218-231.

34. Oderup, C., et al., Cytotoxic $T$ lymphocyte antigen-4-dependent down-modulation of costimulatory molecules on dendritic cells in CD4+ CD25+ regulatory T-cell-mediated suppression. Immunology, 2006. 118(2): p. 240-9.

35. Qureshi, O.S., et al., Trans-endocytosis of CD80 and CD86: a molecular basis for the cellextrinsic function of CTLA-4. Science, 2011. 332(6029): p. 600-3.

36. Liu, Z., et al., Immune homeostasis enforced by co-localized effector and regulatory $T$ cells. Nature, 2015. 528(7581): p. 225-30.

37. Belkaid, Y. and B.T. Rouse, Natural regulatory T cells in infectious disease. Nat Immunol, 2005. 6(4): p. 353-60.

38. Yamaguchi, T. and S. Sakaguchi, Regulatory T cells in immune surveillance and treatment of cancer. Semin Cancer Biol, 2006. 16(2): p. 115-23.

39. Wood, K.J. and S. Sakaguchi, Regulatory T cells in transplantation tolerance. Nat Rev Immunol, 2003. 3(3): p. 199-210.

40. DuPage, M. and J.A. Bluestone, Harnessing the plasticity of $C D 4(+) T$ cells to treat immunemediated disease. Nat Rev Immunol, 2016. 16(3): p. 149-63.

41. Bennett, C.L., et al., The immune dysregulation, polyendocrinopathy, enteropathy, $X$-linked syndrome (IPEX) is caused by mutations of FOXP3. Nat Genet, 2001. 27(1): p. 20-1.

42. Wildin, R.S., et al., X-linked neonatal diabetes mellitus, enteropathy and endocrinopathy syndrome is the human equivalent of mouse scurfy. Nat Genet, 2001. 27(1): p. 18-20.

43. Viglietta, V., et al., Loss of functional suppression by $C D 4+C D 25+$ regulatory $T$ cells in patients with multiple sclerosis. J Exp Med, 2004. 199(7): p. 971-9.

44. Lindley, S., et al., Defective suppressor function in CD4(+)CD25(+) T-cells from patients with type 1 diabetes. Diabetes, 2005. 54(1): p. 92-9.

45. Sugiyama, H., et al., Dysfunctional blood and target tissue $C D 4+C D 25$ high regulatory $T$ cells in psoriasis: mechanism underlying unrestrained pathogenic effector $T$ cell proliferation. J Immunol, 2005. 174(1): p. 164-73.

46. Balandina, A., et al., Functional defect of regulatory $C D 4(+) C D 25+T$ cells in the thymus of patients with autoimmune myasthenia gravis. Blood, 2005. 105(2): p. 735-41. 
47. Akdis, M., et al., Immune responses in healthy and allergic individuals are characterized by a fine balance between allergen-specific T regulatory 1 and T helper 2 cells. J Exp Med, 2004. 199(11): p. 1567-75.

48. Tiemessen, M.M., et al., Cow's milk-specific T-cell reactivity of children with and without persistent cow's milk allergy: key role for IL-10. J Allergy Clin Immunol, 2004. 113(5): p. 932-9.

49. Zhao, J., J. Zhao, and S. Perlman, Virus-specific regulatory $T$ cells ameliorate encephalitis by repressing effector $T$ cell functions from priming to effector stages. PLoS Pathog, 2014. 10(8): p. e1004279.

50. Brincks, E.L., et al., Antigen-specific memory regulatory CD4+Foxp3+ T cells control memory responses to influenza virus infection. J Immunol, 2013. 190(7): p. 3438-46.

51. Munn, D.H., M.D. Sharma, and T.S. Johnson, Treg Destabilization and Reprogramming: Implications for Cancer Immunotherapy. Cancer Res, 2018. 78(18): p. 5191-5199.

52. Yang, X.O., et al., Molecular antagonism and plasticity of regulatory and inflammatory $T$ cell programs. Immunity, 2008. 29(1): p. 44-56.

53. Cabrera, R., et al., An immunomodulatory role for $C D 4(+) C D 25(+)$ regulatory Tlymphocytes in hepatitis $C$ virus infection. Hepatology, 2004. 40(5): p. 1062-71.

54. Stoop, J.N., et al., Regulatory $T$ cells contribute to the impaired immune response in patients with chronic hepatitis B virus infection. Hepatology, 2005. 41(4): p. 771-8.

55. Sugimoto, K., et al., Suppression of HCV-specific $T$ cells without differential hierarchy demonstrated ex vivo in persistent HCV infection. Hepatology, 2003. 38(6): p. 1437-48.

56. Woo, E.Y., et al., Cutting edge: Regulatory $T$ cells from lung cancer patients directly inhibit autologous T cell proliferation. J Immunol, 2002. 168(9): p. 4272-6.

57. Wolf, A.M., et al., Increase of regulatory $T$ cells in the peripheral blood of cancer patients. Clin Cancer Res, 2003. 9(2): p. 606-12.

58. Liyanage, U.K., et al., Prevalence of regulatory $T$ cells is increased in peripheral blood and tumor microenvironment of patients with pancreas or breast adenocarcinoma. J Immunol, 2002. 169(5): p. 2756-61.

59. Viguier, M., et al., Foxp3 expressing $C D 4+C D 25$ (high) regulatory $T$ cells are overrepresented in human metastatic melanoma lymph nodes and inhibit the function of infiltrating $T$ cells. J Immunol, 2004. 173(2): p. 1444-53.

60. Ormandy, L.A., et al., Increased populations of regulatory $T$ cells in peripheral blood of patients with hepatocellular carcinoma. Cancer Res, 2005. 65(6): p. 2457-64.

61. Bos, P.D., et al., Transient regulatory $T$ cell ablation deters oncogene-driven breast cancer and enhances radiotherapy. J Exp Med, 2013. 210(11): p. 2435-66.

62. Jang, J.E., et al., Crosstalk between Regulatory $T$ Cells and Tumor-Associated Dendritic Cells Negates Anti-tumor Immunity in Pancreatic Cancer. Cell Rep, 2017. 20(3): p. 558-571.

63. Shitara, K. and H. Nishikawa, Regulatory $T$ cells: a potential target in cancer immunotherapy. Ann N Y Acad Sci, 2018. 1417(1): p. 104-115.

64. Jonuleit, $H_{\text {., }}$ et al., Dendritic cells as a tool to induce anergic and regulatory $T$ cells. Trends Immunol, 2001. 22(7): p. 394-400.

65. Prakken, B.J., et al., Epitope-specific immunotherapy induces immune deviation of proinflammatory $T$ cells in rheumatoid arthritis. Proc Natl Acad Sci U S A, 2004. 101(12): p. 4228-33.

66. Akdis, C.A., et al., Role of interleukin 10 in specific immunotherapy. J Clin Invest, 1998. 102(1): p. 98-106.

67. Verhoef, A., et al., $T$ cell epitope immunotherapy induces a $C D 4+T$ cell population with regulatory activity. PLoS Med, 2005. 2(3): p. e78.

68. Kappos, L., et al., Induction of a non-encephalitogenic type $2 T$ helper-cell autoimmune response in multiple sclerosis after administration of an altered peptide ligand in a placebocontrolled, randomized phase II trial. The Altered Peptide Ligand in Relapsing MS Study Group. Nat Med, 2000. 6(10): p. 1176-82. 
69. Pedotti, R., et al., Severe anaphylactic reactions to glutamic acid decarboxylase (GAD) self peptides in NOD mice that spontaneously develop autoimmune type 1 diabetes mellitus. BMC Immunol, 2003. 4: p. 2.

70. Belghith, M., et al., TGF-beta-dependent mechanisms mediate restoration of self-tolerance induced by antibodies to CD3 in overt autoimmune diabetes. Nat Med, 2003. 9(9): p. 1202-8.

71. Penaranda, C., Q. Tang, and J.A. Bluestone, Anti-CD3 therapy promotes tolerance by selectively depleting pathogenic cells while preserving regulatory $T$ cells. J Immunol, 2011. 187(4): p. 2015-22.

72. Herold, K.C., et al., A single course of anti-CD3 monoclonal antibody hOKT3gamma1(Ala-Ala) results in improvement in C-peptide responses and clinical parameters for at least 2 years after onset of type 1 diabetes. Diabetes, 2005. 54(6): p. 1763-9.

73. Keymeulen, B., et al., Insulin needs after CD3-antibody therapy in new-onset type 1 diabetes. N Engl J Med, 2005. 352(25): p. 2598-608.

74. Herold, K.C., et al., An Anti-CD3 Antibody, Teplizumab, in Relatives at Risk for Type 1 Diabetes. N Engl J Med, 2019. 381(7): p. 603-613.

75. Tran, G.T., et al., Reversal of experimental allergic encephalomyelitis with non-mitogenic, nondepleting anti-CD3 mAb therapy with a preferential effect on $T(h) 1$ cells that is augmented by IL-4. Int Immunol, 2001. 13(9): p. 1109-20.

76. Kohm, A.P., et al., Treatment with nonmitogenic anti-CD3 monoclonal antibody induces CD4+ $T$ cell unresponsiveness and functional reversal of established experimental autoimmune encephalomyelitis. J Immunol, 2005. 174(8): p. 4525-34.

77. Ludviksson, B.R., R.O. Ehrhardt, and W. Strober, TGF-beta production regulates the development of the 2,4,6-trinitrophenol-conjugated keyhole limpet hemocyanin-induced colonic inflammation in IL-2-deficient mice. J Immunol, 1997. 159(7): p. 3622-8.

78. Hughes, C., et al., Induction of Thelper cell hyporesponsiveness in an experimental model of autoimmunity by using nonmitogenic anti-CD3 monoclonal antibody. J Immunol, 1994. 153(7): p. 3319-25.

79. You, S., et al., Induction of allograft tolerance by monoclonal CD3 antibodies: a matter of timing. Am J Transplant, 2012. 12(11): p. 2909-19.

80. Gregori, S., et al., An anti-CD45RO/RB monoclonal antibody modulates $T$ cell responses via induction of apoptosis and generation of regulatory T cells. J Exp Med, 2005. 201(8): p. 1293305.

81. Picarda, E., et al., Transient antibody targeting of CD45RC induces transplant tolerance and potent antigen-specific regulatory T cells. JCI Insight, 2017. 2(3): p. e90088.

82. Segundo, D.S., et al., Calcineurin inhibitors, but not rapamycin, reduce percentages of CD4+CD25+FOXP3+ regulatory $T$ cells in renal transplant recipients. Transplantation, 2006. 82(4): p. 550-7.

83. Hartemann, A., et al., Low-dose interleukin 2 in patients with type 1 diabetes: a phase 1/2 randomised, double-blind, placebo-controlled trial. Lancet Diabetes Endocrinol, 2013. 1(4): p. 295-305.

84. Matsuoka, K., et al., Low-dose interleukin-2 therapy restores regulatory $T$ cell homeostasis in patients with chronic graft-versus-host disease. Sci Transl Med, 2013. 5(179): p. 179 ra43.

85. Liu, C.L., et al., In vivo expansion of regulatory $T$ cells with IL-2/IL-2 mAb complexes prevents anti-factor VIII immune responses in hemophilia A mice treated with factor VIII plasmidmediated gene therapy. Mol Ther, 2011. 19(8): p. 1511-20.

86. Liu, C.L., et al., Long-term tolerance to factor VIII is achieved by administration of interleukin2/interleukin-2 monoclonal antibody complexes and low dosages of factor VIII. J Thromb Haemost, 2014. 12(6): p. 921-31.

87. Zhang, H., et al., In Vivo Expansion of Regulatory $T$ Cells with IL-2/IL-2 Antibody Complex Protects against Transient Ischemic Stroke. J Neurosci, 2018. 38(47): p. 10168-10179. 
88. Burmester, G.R. and J.E. Pope, Novel treatment strategies in rheumatoid arthritis. Lancet, 2017. 389(10086): p. 2338-2348.

89. Monaco, C., et al., Anti-TNF therapy: past, present and future. Int Immunol, 2015. 27(1): p. 5562.

90. Godfrey, W.R., et al., In vitro-expanded human CD4(+)CD25(+) T-regulatory cells can markedly inhibit allogeneic dendritic cell-stimulated MLR cultures. Blood, 2004. 104(2): p. 453-61.

91. Hoffmann, P., et al., Large-scale in vitro expansion of polyclonal human CD4(+)CD25high regulatory T cells. Blood, 2004. 104(3): p. 895-903.

92. Chai, J.G., et al., In vitro expansion improves in vivo regulation by $C D 4+C D 25+$ regulatory $T$ cells. J Immunol, 2008. 180(2): p. 858-69.

93. Lin, C.H. and T. Hunig, Efficient expansion of regulatory $T$ cells in vitro and in vivo with a CD28 superagonist. Eur J Immunol, 2003. 33(3): p. 626-38.

94. Sakaguchi, S., et al., Immunologic self-tolerance maintained by activated T cells expressing IL2 receptor alpha-chains (CD25). Breakdown of a single mechanism of self-tolerance causes various autoimmune diseases. J Immunol, 1995. 155(3): p. 1151-64.

95. Edinger, M., et al., $C D 4+C D 25+$ regulatory $T$ cells preserve graft-versus-tumor activity while inhibiting graft-versus-host disease after bone marrow transplantation. Nat Med, 2003. 9(9): p. 1144-50.

96. Cohen, J.L., et al., CD4(+)CD25(+) immunoregulatory T Cells: new therapeutics for graft-versushost disease. J Exp Med, 2002. 196(3): p. 401-6.

97. Taylor, P.A., C.J. Lees, and B.R. Blazar, The infusion of ex vivo activated and expanded CD4(+)CD25(+) immune regulatory cells inhibits graft-versus-host disease lethality. Blood, 2002. 99(10): p. 3493-9.

98. Xia, G., J. He, and J.R. Leventhal, Ex vivo-expanded natural CD4+CD25+ regulatory $T$ cells synergize with host $T$-cell depletion to promote long-term survival of allografts. Am J Transplant, 2008. 8(2): p. 298-306.

99. Xiao, F., et al., Ex vivo expanded human regulatory $T$ cells delay islet allograft rejection via inhibiting islet-derived monocyte chemoattractant protein-1 production in CD34+ stem cellsreconstituted NOD-scid IL2rgammanull mice. PLoS One, 2014. 9(3): p. e90387.

100. Canavan, J.B., et al., Developing in vitro expanded CD45RA+ regulatory $T$ cells as an adoptive cell therapy for Crohn's disease. Gut, 2016. 65(4): p. 584-94.

101. Scalapino, K.J., et al., Suppression of disease in New Zealand Black/New Zealand White lupusprone mice by adoptive transfer of ex vivo expanded regulatory $T$ cells. J Immunol, 2006. 177(3): p. 1451-9.

102. Marek-Trzonkowska, N., et al., Administration of CD4+CD25highCD127- regulatory $T$ cells preserves beta-cell function in type 1 diabetes in children. Diabetes Care, 2012. 35(9): p. 181720.

103. Bluestone, J.A., et al., Type 1 diabetes immunotherapy using polyclonal regulatory $T$ cells. Sci Transl Med, 2015. 7(315): p. 315ra189.

104. Mathew, J.M., et al., A Phase I Clinical Trial with Ex Vivo Expanded Recipient Regulatory T cells in Living Donor Kidney Transplants. Sci Rep, 2018. 8(1): p. 7428.

105. Trzonkowski, P., et al., First-in-man clinical results of the treatment of patients with graft versus host disease with human ex vivo expanded $C D 4+C D 25+C D 127-T$ regulatory cells. Clin Immunol, 2009. 133(1): p. 22-6.

106. Di lanni, M., et al., Tregs prevent GVHD and promote immune reconstitution in HLAhaploidentical transplantation. Blood, 2011. 117(14): p. 3921-8.

107. Martelli, M.F., et al., HLA-haploidentical transplantation with regulatory and conventional Tcell adoptive immunotherapy prevents acute leukemia relapse. Blood, 2014. 124(4): p. 638-44.

108. Li, J., et al., Regulatory T-Cells: Potential Regulator of Tissue Repair and Regeneration. Front Immunol, 2018. 9: p. 585.

109. Panduro, M., C. Benoist, and D. Mathis, Tissue Tregs. Annu Rev Immunol, 2016. 34: p. 609-33. 
110. Miao, C.H., et al., CD4+FOXP3+ regulatory $T$ cells confer long-term regulation of factor VIIIspecific immune responses in plasmid-mediated gene therapy-treated hemophilia mice. Blood, 2009. 114(19): p. 4034-44.

111. Sarkar, D., et al., Ex Vivo Expanded Autologous Polyclonal Regulatory T Cells Suppress Inhibitor Formation in Hemophilia. Mol Ther Methods Clin Dev, 2014. 1.

112. Esensten, J.H., et al., Regulatory T-cell therapy for autoimmune and autoinflammatory diseases: The next frontier. J Allergy Clin Immunol, 2018. 142(6): p. 1710-1718.

113. Riley, J.L., C.H. June, and B.R. Blazar, Human T regulatory cell therapy: take a billion or so and call me in the morning. Immunity, 2009. 30(5): p. 656-65.

114. Hori, S., T. Nomura, and S. Sakaguchi, Control of regulatory $T$ cell development by the transcription factor Foxp3. Science, 2003. 299(5609): p. 1057-61.

115. Jaeckel, E., H. von Boehmer, and M.P. Manns, Antigen-specific FoxP3-transduced T-cells can control established type 1 diabetes. Diabetes, 2005. 54(2): p. 306-10.

116. Passerini, L., et al., CD4(+) T cells from IPEX patients convert into functional and stable regulatory T cells by FOXP3 gene transfer. Sci Transl Med, 2013. 5(215): p. 215 ra174.

117. Herzog, R.W., et al., Reprogrammed CD4(+) T Cells That Express FoxP3(+) Control Inhibitory Antibody Formation in Hemophilia A Mice. Front Immunol, 2019. 10: p. 274.

118. Loser, K., et al., In vitro-generated regulatory $T$ cells induced by Foxp3-retrovirus infection control murine contact allergy and systemic autoimmunity. Gene Ther, 2005. 12(17): p. 1294304.

119. Wang, Y.M., et al., Foxp3-transduced polyclonal regulatory T cells protect against chronic renal injury from adriamycin. J Am Soc Nephrol, 2006. 17(3): p. 697-706.

120. Andersen, K.G., T. Butcher, and A.G. Betz, Specific immunosuppression with inducible Foxp3transduced polyclonal T cells. PLoS Biol, 2008. 6(11): p. e276.

121. Honaker, Y., et al., Enabling Gene-Edited, Regulatory-like, T Cells (edTreg) for Treatment of IPEX and Other Autoimmune Disorders. Blood, 2019. 134(Supplement_1): p. 2071-2071.

122. Goodwin, M., et al., CRISPR-based gene editing enables $<e m>F O X P 3</ e m>$ gene repair in IPEX patient cells. Science Advances, 2020. 6(19): p. eaaz0571.

123. Shen, W., et al., [Effect of PTD-deltaPRD Foxp3 fusion protein on the mixed lymphocyte reaction in mice]. Zhong Nan Da Xue Xue Bao Yi Xue Ban, 2009. 34(12): p. 1224-30.

124. Liu, X., et al., PTD-hFOXP3 protein acts as an immune regulator to convert human CD4(+)CD25(-) T cells to regulatory T-like cells. J Cell Biochem, 2012. 113(12): p. 3797-809.

125. Choi, J.M., et al., Cell-permeable Foxp3 protein alleviates autoimmune disease associated with inflammatory bowel disease and allergic airway inflammation. Proc Natl Acad Sci U S A, 2010. 107(43): p. 18575-80.

126. Liu, X., et al., Cell-penetrable mouse forkhead box protein 3 alleviates experimental arthritis in mice by up-regulating regulatory T cells. Clin Exp Immunol, 2015. 181(1): p. 87-99.

127. Brunstein, C.G., et al., Adoptive transfer of umbilical cord blood-derived regulatory $T$ cells and early viral reactivation. Biol Blood Marrow Transplant, 2013. 19(8): p. 1271-3.

128. Joffre, O., et al., Prevention of acute and chronic allograft rejection with $C D 4+C D 25+F o x p 3+$ regulatory T lymphocytes. Nat Med, 2008. 14(1): p. 88-92.

129. Golshayan, D., et al., In vitro-expanded donor alloantigen-specific CD4+CD25+ regulatory $T$ cells promote experimental transplantation tolerance. Blood, 2007. 109(2): p. 827-35.

130. Trenado, A., et al., Ex vivo-expanded CD4+CD25+ immunoregulatory $T$ cells prevent graftversus-host-disease by inhibiting activation/differentiation of pathogenic $T$ cells. J Immunol, 2006. 176(2): p. 1266-73.

131. Green, E.A., Y. Choi, and R.A. Flavell, Pancreatic lymph node-derived CD4(+)CD25(+) Treg cells: highly potent regulators of diabetes that require TRANCE-RANK signals. Immunity, 2002. 16(2): p. 183-91.

132. Masteller, E.L., et al., Expansion of functional endogenous antigen-specific CD4+CD25+ regulatory $T$ cells from nonobese diabetic mice. J Immunol, 2005. 175(5): p. 3053-9. 
133. Tarbell, K.V., et al., Dendritic cell-expanded, islet-specific CD4+CD25+CD62L+ regulatory $T$ cells restore normoglycemia in diabetic NOD mice. J Exp Med, 2007. 204(1): p. 191-201.

134. Jiang, S., et al., Induction of allopeptide-specific human $C D 4+C D 25+$ regulatory $T$ cells ex vivo. Blood, 2003. 102(6): p. 2180-6.

135. Putnam, A.L., et al., Clinical grade manufacturing of human alloantigen-reactive regulatory $T$ cells for use in transplantation. Am J Transplant, 2013. 13(11): p. 3010-20.

136. Sagoo, P., et al., Human regulatory $T$ cells with alloantigen specificity are more potent inhibitors of alloimmune skin graft damage than polyclonal regulatory T cells. Sci Transl Med, 2011. 3(83): p. 83ra42.

137. Smith, B.M., et al., Antigen-specific in vitro expansion of factor VIII-specific regulatory $T$ cells induces tolerance in hemophilia A mice. J Thromb Haemost, 2020. 18(2): p. 328-340.

138. Hoyer, L.W., Hemophilia A. N Engl J Med, 1994. 330(1): p. 38-47.

139. Kint, J.A., Fabry's disease: alpha-galactosidase deficiency. Science, 1970. 167(3922): p. 12689.

140. Muller-Felber, W., et al., Late onset Pompe disease: clinical and neurophysiological spectrum of 38 patients including long-term follow-up in 18 patients. Neuromuscul Disord, 2007. 17(910): p. 698-706.

141. Tang, Q. and K. Lee, Regulatory T-cell therapy for transplantation: how many cells do we need? Curr Opin Organ Transplant, 2012. 17(4): p. 349-54.

142. Bonini, C. and A. Mondino, Adoptive T-cell therapy for cancer: The era of engineered $T$ cells. Eur J Immunol, 2015. 45(9): p. 2457-69.

143. Blat, D., et al., Suppression of murine colitis and its associated cancer by carcinoembryonic antigen-specific regulatory T cells. Mol Ther, 2014. 22(5): p. 1018-28.

144. Fransson, M., et al., CAR/FoxP3-engineered Tregulatory cells target the CNS and suppress EAE upon intranasal delivery. J Neuroinflammation, 2012. 9: p. 112.

145. Jethwa, H., A.A. Adami, and J. Maher, Use of gene-modified regulatory T-cells to control autoimmune and alloimmune pathology: is now the right time? Clin Immunol, 2014. 150(1): p. 51-63.

146. Wright, G.P., et al., Adoptive therapy with redirected primary regulatory $T$ cells results in antigen-specific suppression of arthritis. Proc Natl Acad Sci U S A, 2009. 106(45): p. 19078-83.

147. Tsang, J.Y., et al., Conferring indirect allospecificity on CD4+CD25+ Tregs by TCR gene transfer favors transplantation tolerance in mice. J Clin Invest, 2008. 118(11): p. 3619-28.

148. Kim, Y.C., et al., Engineered antigen-specific human regulatory $T$ cells: immunosuppression of FVIII-specific T- and B-cell responses. Blood, 2015. 125(7): p. 1107-15.

149. Hull, C.M., et al., Generation of human islet-specific regulatory T cells by TCR gene transfer. J Autoimmun, 2017. 79: p. 63-73.

150. Spence, A., et al., Revealing the specificity of regulatory T cells in murine autoimmune diabetes. Proc Natl Acad Sci U S A, 2018. 115(20): p. 5265-5270.

151. Guedan, S., et al., Engineering and Design of Chimeric Antigen Receptors. Mol Ther Methods Clin Dev, 2019. 12: p. 145-156.

152. Sommermeyer, D., et al., Fully human CD19-specific chimeric antigen receptors for T-cell therapy. Leukemia, 2017. 31(10): p. 2191-2199.

153. Boardman, D.A. and M.K. Levings, Cancer immunotherapies repurposed for use in autoimmunity. Nat Biomed Eng, 2019. 3(4): p. 259-263.

154. Lee, J.C., et al., In vivo inhibition of human CD19-targeted effector $T$ cells by natural $T$ regulatory cells in a xenotransplant murine model of B cell malignancy. Cancer Res, 2011. 71(8): p. 2871-81.

155. Elinav, E., T. Waks, and Z. Eshhar, Redirection of regulatory $T$ cells with predetermined specificity for the treatment of experimental colitis in mice. Gastroenterology, 2008. 134(7): p. 2014-24. 
156. Hombach, A.A., et al., Redirecting human $C D 4+C D 25+$ regulatory $T$ cells from the peripheral blood with pre-defined target specificity. Gene Ther, 2009. 16(9): p. 1088-96.

157. Elinav, E., et al., Amelioration of colitis by genetically engineered murine regulatory $T$ cells redirected by antigen-specific chimeric receptor. Gastroenterology, 2009. 136(5): p. 1721-31.

158. MacDonald, K.G., et al., Alloantigen-specific regulatory $T$ cells generated with a chimeric antigen receptor. J Clin Invest, 2016. 126(4): p. 1413-24.

159. Noyan, F., et al., Prevention of Allograft Rejection by Use of Regulatory T Cells With an MHCSpecific Chimeric Antigen Receptor. Am J Transplant, 2017. 17(4): p. 917-930.

160. Pierini, A., et al., $T$ cells expressing chimeric antigen receptor promote immune tolerance. $\mathrm{JCI}$ Insight, 2017. 2(20).

161. Dawson, N.A., et al., Systematic testing and specificity mapping of alloantigen-specific chimeric antigen receptors in regulatory T cells. JCI Insight, 2019. 4(6).

162. Boardman, D.A., et al., Expression of a Chimeric Antigen Receptor Specific for Donor HLA Class I Enhances the Potency of Human Regulatory T Cells in Preventing Human Skin Transplant Rejection. Am J Transplant, 2017. 17(4): p. 931-943.

163. Yoon, J., et al., FVIII-specific human chimeric antigen receptor T-regulatory cells suppress $T$ and B-cell responses to FVIII. Blood, 2017. 129(2): p. 238-245.

164. Raffin, C., et al., Development of citrullinated-vimentin-specific CAR for targeting Tregs to treat autoimmune rheumatoid arthritis. The Journal of Immunology, 2018. 200(1 Supplement): p. 176.17-176.17.

165. Grossman, W.J., et al., Human T regulatory cells can use the perforin pathway to cause autologous target cell death. Immunity, 2004. 21(4): p. 589-601.

166. Tenspolde, M., et al., Regulatory $T$ cells engineered with a novel insulin-specific chimeric antigen receptor as a candidate immunotherapy for type 1 diabetes. J Autoimmun, 2019. 103: p. 102289.

167. Zhang, A.H., et al., Targeting Antigen-Specific B Cells Using Antigen-Expressing Transduced Regulatory T Cells. J Immunol, 2018. 201(5): p. 1434-1441.

168. Pohl, A.P., et al., Suppression of FVIII-Specific Memory B Cells by Chimeric BAR ReceptorEngineered Natural Regulatory T Cells. Front Immunol, 2020. 11: p. 693.

169. Ohkura, N., et al., T cell receptor stimulation-induced epigenetic changes and Foxp3 expression are independent and complementary events required for Treg cell development. Immunity, 2012. 37(5): p. 785-99.

170. Samstein, R.M., et al., Foxp3 exploits a pre-existent enhancer landscape for regulatory $T$ cell lineage specification. Cell, 2012. 151(1): p. 153-66.

171. Nie, H., et al., Phosphorylation of FOXP3 controls regulatory $T$ cell function and is inhibited by TNF-alpha in rheumatoid arthritis. Nat Med, 2013. 19(3): p. 322-8.

172. Qiu, R., et al., Regulatory T Cell Plasticity and Stability and Autoimmune Diseases. Clin Rev Allergy Immunol, 2020. 58(1): p. 52-70.

173. Sakaguchi, S., et al., The plasticity and stability of regulatory T cells. Nat Rev Immunol, 2013. 13(6): p. 461-7.

174. Cobbold, S.P., et al., Immune privilege induced by regulatory $T$ cells in transplantation tolerance. Immunol Rev, 2006. 213: p. 239-55.

175. Qin, S., et al., "Infectious" transplantation tolerance. Science, 1993. 259(5097): p. 974-7.

176. Daley, S.R., et al., A key role for TGF-beta signaling to $T$ cells in the long-term acceptance of allografts. J Immunol, 2007. 179(6): p. 3648-54.

177. Andersson, J., et al., CD4+ FoxP3+ regulatory T cells confer infectious tolerance in a TGF-betadependent manner. J Exp Med, 2008. 205(9): p. 1975-81.

178. Cobbold, S.P., et al., Infectious tolerance via the consumption of essential amino acids and mTOR signaling. Proc Natl Acad Sci U S A, 2009. 106(29): p. 12055-60.

179. Gravano, D.M. and D.A. Vignali, The battle against immunopathology: infectious tolerance mediated by regulatory T cells. Cell Mol Life Sci, 2012. 69(12): p. 1997-2008. 
180. Salmikangas, P., N. Kinsella, and P. Chamberlain, Chimeric Antigen Receptor T-Cells (CAR TCells) for Cancer Immunotherapy - Moving Target for Industry? Pharm Res, 2018. 35(8): p. 152.

181. Kawalekar, O.U., et al., Distinct Signaling of Coreceptors Regulates Specific Metabolism Pathways and Impacts Memory Development in CAR T Cells. Immunity, 2016. 44(3): p. 712.

182. Long, A.H., et al., 4-1BB costimulation ameliorates $T$ cell exhaustion induced by tonic signaling of chimeric antigen receptors. Nat Med, 2015. 21(6): p. 581-90.

183. Porter, D.L., et al., Chimeric antigen receptor $T$ cells persist and induce sustained remissions in relapsed refractory chronic lymphocytic leukemia. Sci Transl Med, 2015. 7(303): p. 303ra139.

184. Guedan, S., et al., ICOS-based chimeric antigen receptors program bipolar TH17/TH1 cells. Blood, 2014. 124(7): p. 1070-80.

185. Guedan, S., et al., Enhancing CAR T cell persistence through ICOS and 4-1BB costimulation. JCI Insight, 2018. 3(1).

186. Hombach, A.A., et al., OX40 costimulation by a chimeric antigen receptor abrogates CD28 and IL-2 induced IL-10 secretion by redirected CD4(+) T cells. Oncoimmunology, 2012. 1(4): p. 458466.

187. Fedorov, V.D., M. Themeli, and M. Sadelain, PD-1- and CTLA-4-based inhibitory chimeric antigen receptors (iCARs) divert off-target immunotherapy responses. Sci Transl Med, 2013. 5(215): p. 215ra172.

188. de Kouchkovsky, D., et al., microRNA-17-92 regulates IL-10 production by regulatory $T$ cells and control of experimental autoimmune encephalomyelitis. J Immunol, 2013. 191(4): p. 1594605.

189. Salomon, B., et al., $B 7 / C D 28$ costimulation is essential for the homeostasis of the CD4+CD25+ immunoregulatory $T$ cells that control autoimmune diabetes. Immunity, 2000. 12(4): p. 43140.

190. Song, D.G., et al., In vivo persistence, tumor localization, and antitumor activity of CARengineered T cells is enhanced by costimulatory signaling through CD137 (4-1BB). Cancer Res, 2011. 71(13): p. 4617-27.

191. Boroughs, A.C., et al., Chimeric antigen receptor costimulation domains modulate human regulatory $T$ cell function. JCI Insight, 2019. 5.

192. Lee, J., et al., Administration of agonistic anti-4-1BB monoclonal antibody leads to the amelioration of inflammatory bowel disease. Immunol Lett, 2005. 101(2): p. 210-6.

193. Sun, Y., et al., Administration of agonistic anti-4-1BB monoclonal antibody leads to the amelioration of experimental autoimmune encephalomyelitis. J Immunol, 2002. 168(3): p. 1457-65.

194. Zhang, P., et al., Agonistic anti-4-1BB antibody promotes the expansion of natural regulatory $T$ cells while maintaining Foxp3 expression. Scand J Immunol, 2007. 66(4): p. 435-40.

195. Smith, S.E., et al., Signals through 4-1BB inhibit T regulatory cells by blocking IL-9 production enhancing antitumor responses. Cancer Immunol Immunother, 2011. 60(12): p. 1775-87.

196. Buchan, S.L., et al., Antibodies to Costimulatory Receptor 4-1BB Enhance Anti-tumor Immunity via T Regulatory Cell Depletion and Promotion of CD8 T Cell Effector Function. Immunity, 2018. 49(5): p. 958-970 e7.

197. Akhmetzyanova, I., et al., CD137 Agonist Therapy Can Reprogram Regulatory T Cells into Cytotoxic CD4+ T Cells with Antitumor Activity. J Immunol, 2016. 196(1): p. 484-92.

198. Zhao, Z., et al., Structural Design of Engineered Costimulation Determines Tumor Rejection Kinetics and Persistence of CAR T Cells. Cancer Cell, 2015. 28(4): p. 415-428.

199. Ramos, C.A., et al., In Vivo Fate and Activity of Second-versus Third-Generation CD19-Specific CAR-T Cells in B Cell Non-Hodgkin's Lymphomas. Mol Ther, 2018. 26(12): p. 2727-2737.

200. Quintarelli, C., et al., Choice of costimulatory domains and of cytokines determines CAR T-cell activity in neuroblastoma. Oncoimmunology, 2018. 7(6): p. e1433518.

201. Gill, S. and C.H. June, Going viral: chimeric antigen receptor T-cell therapy for hematological malignancies. Immunol Rev, 2015. 263(1): p. 68-89. 
202. Yan, D., et al., Imbalanced signal transduction in regulatory $T$ cells expressing the transcription factor FoxP3. Proc Natl Acad Sci U S A, 2015. 112(48): p. 14942-7.

203. Gottschalk, R.A., E. Corse, and J.P. Allison, TCR ligand density and affinity determine peripheral induction of Foxp3 in vivo. J Exp Med, 2010. 207(8): p. 1701-11.

204. Caruso, H.G., et al., Tuning Sensitivity of CAR to EGFR Density Limits Recognition of Normal Tissue While Maintaining Potent Antitumor Activity. Cancer Res, 2015. 75(17): p. 3505-18.

205. Ghorashian, S., et al., Enhanced CAR T cell expansion and prolonged persistence in pediatric patients with ALL treated with a low-affinity CD19 CAR. Nat Med, 2019. 25(9): p. 1408-1414.

206. Sprouse, M.L., et al., Cutting Edge: Low-Affinity TCRs Support Regulatory T Cell Function in Autoimmunity. J Immunol, 2018. 200(3): p. 909-914.

207. Varela-Rohena, A., et al., Control of HIV-1 immune escape by CD8 T cells expressing enhanced T-cell receptor. Nat Med, 2008. 14(12): p. 1390-5.

208. Alexander-Miller, M.A., High-avidity CD8+ T cells: optimal soldiers in the war against viruses and tumors. Immunol Res, 2005. 31(1): p. 13-24.

209. Derby, M., et al., High-avidity CTL exploit two complementary mechanisms to provide better protection against viral infection than low-avidity CTL. J Immunol, 2001. 166(3): p. 1690-7.

210. Jorritsma, A., et al., Selecting highly affine and well-expressed TCRs for gene therapy of melanoma. Blood, 2007. 110(10): p. 3564-72.

211. Tsang, J.Y., et al., The potency of allospecific Tregs cells appears to correlate with T cell receptor functional avidity. Am J Transplant, 2011. 11(8): p. 1610-20.

212. Eyquem, J., et al., Targeting a CAR to the TRAC locus with CRISPR/Cas9 enhances tumour rejection. Nature, 2017. 543(7643): p. 113-117.

213. MacLeod, D.T., et al., Integration of a CD19 CAR into the TCR Alpha Chain Locus Streamlines Production of Allogeneic Gene-Edited CAR T Cells. Mol Ther, 2017. 25(4): p. 949-961.

214. Wei, J., et al., Target selection for CAR-T therapy. J Hematol Oncol, 2019. 12(1): p. 62.

215. Hegde, M., et al., Combinational targeting offsets antigen escape and enhances effector functions of adoptively transferred T cells in glioblastoma. Mol Ther, 2013. 21(11): p. 2087101.

216. Ruella, M., et al., Dual CD19 and CD123 targeting prevents antigen-loss relapses after CD19directed immunotherapies. J Clin Invest, 2016. 126(10): p. 3814-3826.

217. Zah, E., et al., T Cells Expressing CD19/CD20 Bispecific Chimeric Antigen Receptors Prevent Antigen Escape by Malignant B Cells. Cancer Immunol Res, 2016. 4(6): p. 498-508.

218. Grada, Z., et al., TanCAR: A Novel Bispecific Chimeric Antigen Receptor for Cancer Immunotherapy. Mol Ther Nucleic Acids, 2013. 2: p. e105.

219. Hegde, M., et al., Tandem CAR T cells targeting HER2 and IL13Ralpha2 mitigate tumor antigen escape. J Clin Invest, 2016. 126(8): p. 3036-52.

220. Lanitis, E., et al., Chimeric antigen receptor T Cells with dissociated signaling domains exhibit focused antitumor activity with reduced potential for toxicity in vivo. Cancer Immunol Res, 2013. 1(1): p. 43-53.

221. Roybal, K.T., et al., Precision Tumor Recognition by T Cells With Combinatorial Antigen-Sensing Circuits. Cell, 2016. 164(4): p. 770-9.

222. Sukumaran, S., et al., Enhancing the Potency and Specificity of Engineered T Cells for Cancer Treatment. Cancer Discov, 2018. 8(8): p. 972-987.

223. Di Stasi, A., et al., $T$ lymphocytes coexpressing CCR4 and a chimeric antigen receptor targeting CD30 have improved homing and antitumor activity in a Hodgkin tumor model. Blood, 2009. 113(25): p. 6392-402.

224. Condomines, M., et al., Tumor-Targeted Human T Cells Expressing CD28-Based Chimeric Antigen Receptors Circumvent CTLA-4 Inhibition. PLoS One, 2015. 10(6): p. e0130518.

225. Curran, K.J., et al., Enhancing antitumor efficacy of chimeric antigen receptor $T$ cells through constitutive CD40L expression. Mol Ther, 2015. 23(4): p. 769-78. 
226. Hoyos, V., et al., Engineering CD19-specific T lymphocytes with interleukin-15 and a suicide gene to enhance their anti-lymphoma/leukemia effects and safety. Leukemia, 2010. 24(6): p. 1160-70.

227. Chmielewski, M. and H. Abken, TRUCKs: the fourth generation of CARs. Expert Opin Biol Ther, 2015. 15(8): p. 1145-54.

1059

1060

1061

1062

1063

1064

1065

1066

1067

1068

1069

228. Koneru, M., et al., IL-12 secreting tumor-targeted chimeric antigen receptor $T$ cells eradicate ovarian tumors in vivo. Oncoimmunology, 2015. 4(3): p. e994446.

229. Pegram, H.J., et al., Tumor-targeted T cells modified to secrete IL-12 eradicate systemic tumors without need for prior conditioning. Blood, 2012. 119(18): p. 4133-41.

230. Hurton, L.V., et al., Tethered IL-15 augments antitumor activity and promotes a stem-cell memory subset in tumor-specific T cells. Proc Natl Acad Sci U S A, 2016. 113(48): p. E7788E7797.

231. Markley, J.C. and M. Sadelain, IL-7 and IL-21 are superior to IL-2 and IL-15 in promoting human $T$ cell-mediated rejection of systemic lymphoma in immunodeficient mice. Blood, 2010. 115(17): p. 3508-19.

1070 
1072 Figure 1

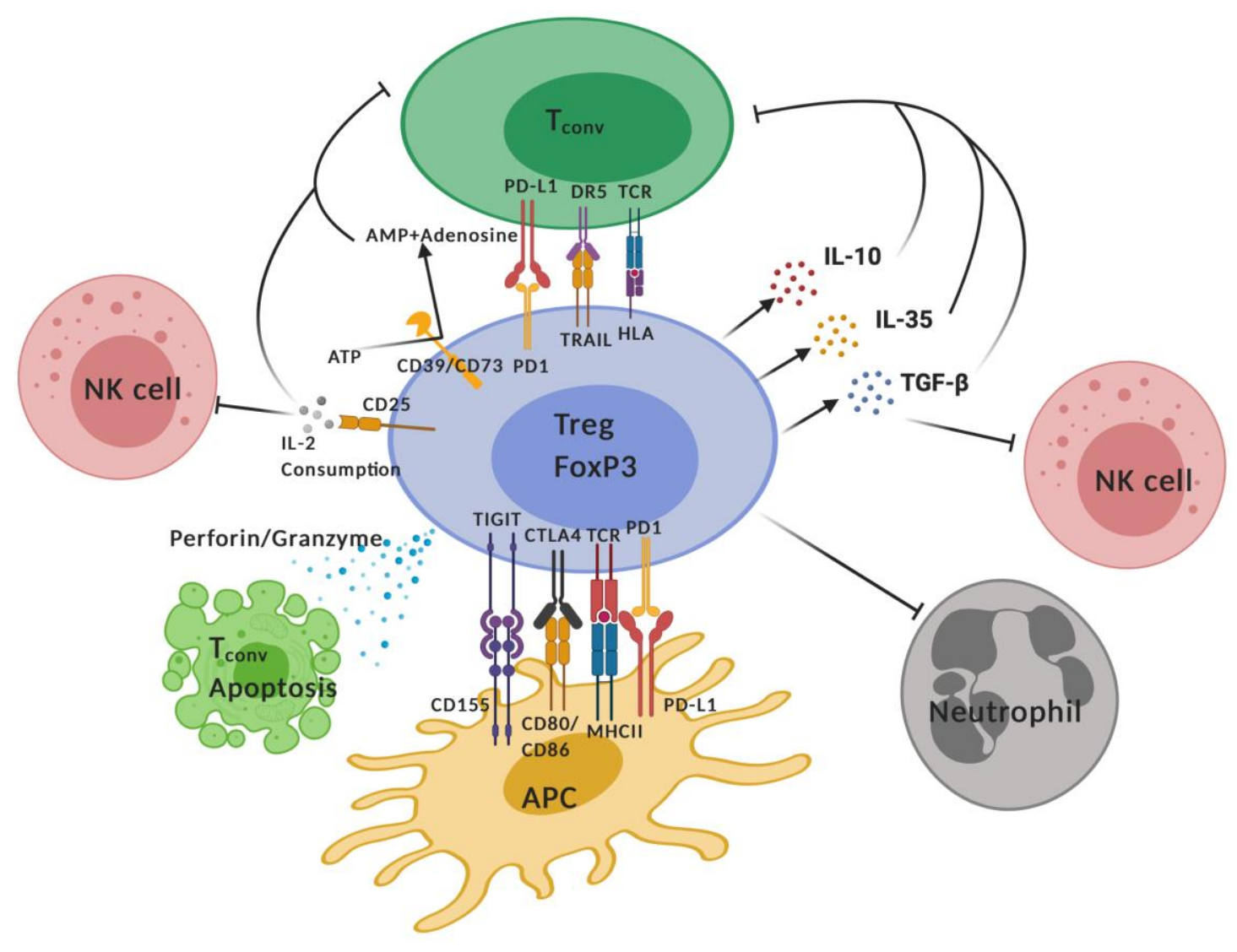




\section{Figure 2}

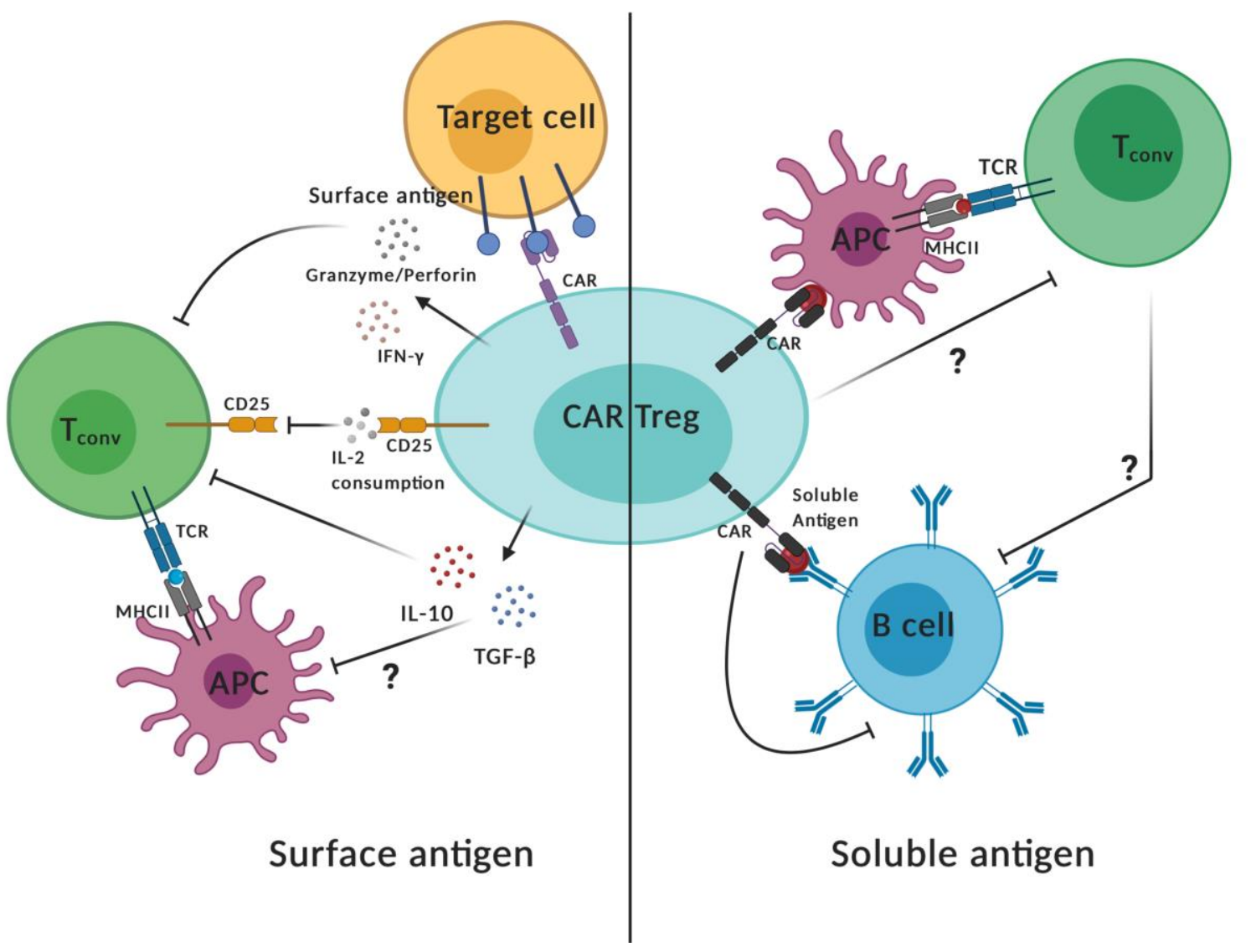




\section{$1076 \quad$ Figure 3}

A

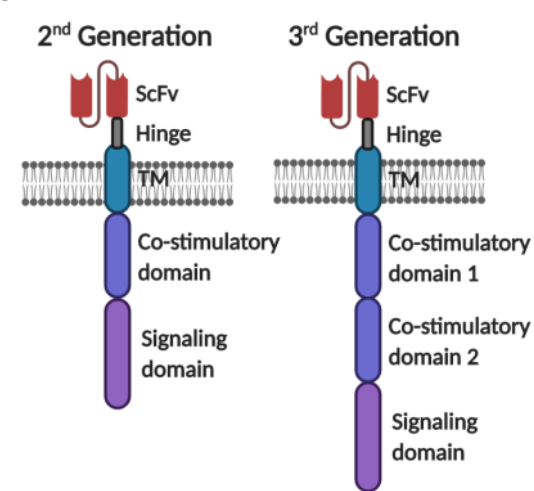

B
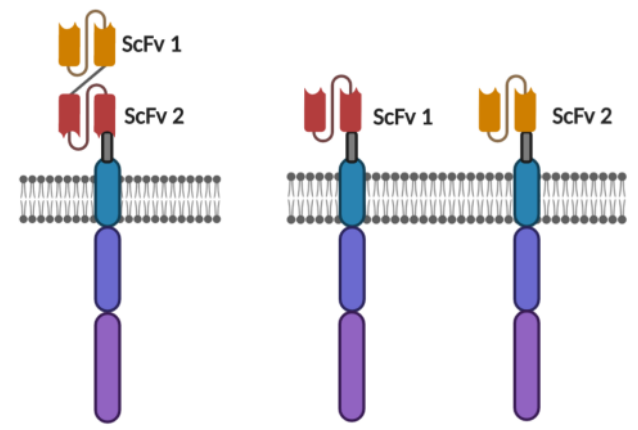

C

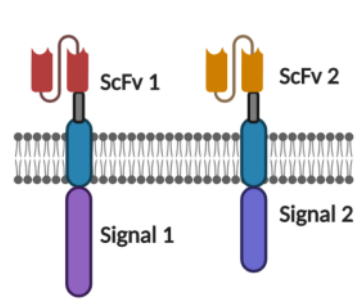

1077

1078 


\section{Table 1: Completed and on-going clinical trials with polyclonal Treg infusions in 1080 different diseases}

\begin{tabular}{|c|c|c|c|c|c|c|}
\hline Study ID & Phase & Enrollment & $\begin{array}{l}\text { Age } \\
\text { (in years) }\end{array}$ & Product & Dose & Status \\
\hline \multicolumn{7}{|l|}{$\begin{array}{l}\text { Type I } \\
\text { diabetes }\end{array}$} \\
\hline NCT01210664 & I & 14 & $18-45$ & $\begin{array}{l}\text { Autologous } \\
\text { polyclonally } \\
\text { expanded Tregs }\end{array}$ & $\begin{array}{l}0.05,0.4, \\
3.2 \text { and } 26 \times \\
10 \mathrm{e} 8\end{array}$ & Completed \\
\hline ISRCTN06128462 & $\mathrm{I}$ & 12 & $5-28$ & $\begin{array}{l}\text { Autologous } \\
\text { polyclonally } \\
\text { expanded Tregs }\end{array}$ & $\begin{array}{l}10 \text { and } 30 \mathrm{x} \\
10 \mathrm{e} 6 / \mathrm{Kg}\end{array}$ & Completed \\
\hline NCT02691247 & II & 113 & $8-17$ & $\begin{array}{l}\text { Autologous } \\
\text { polyclonally } \\
\text { expanded Tregs }\end{array}$ & $\begin{array}{l}2.5 \text { and } 20 x \\
10 \mathrm{e} 6 / \mathrm{Kg}\end{array}$ & Active, not recruiting \\
\hline NCT02772679 & $\mathrm{I}$ & 16 & $18-45$ & $\begin{array}{l}\text { Autologous } \\
\text { polyclonally } \\
\text { expanded Tregs }\end{array}$ & $\begin{array}{l}3 \text { and } 20 x \\
10 \mathrm{e} 6 / \mathrm{Kg}\end{array}$ & Recruiting \\
\hline NCT03011201 & $\mathrm{I} / \mathrm{II}$ & 40 & $>18$ & $\begin{array}{l}\text { UCB Polyclonally } \\
\text { expanded Treg }\end{array}$ & $2 \times 10 \mathrm{e} 6 / \mathrm{Kg}$ & Recruiting \\
\hline NCT02932826 & $\mathrm{I} / \mathrm{II}$ & 40 & $6-16$ & $\begin{array}{l}\text { UCB Polyclonally } \\
\text { expanded Treg }\end{array}$ & $2 \times 10 \mathrm{e} 6 / \mathrm{Kg}$ & Recruiting \\
\hline NCT03444064 & $\mathrm{I}$ & 18 & $18-68$ & $\begin{array}{l}\text { Autologous } \\
\text { polyclonally } \\
\text { expanded Tregs }\end{array}$ & $4-16 \times 10 \mathrm{e} 8$ & Recruiting \\
\hline \multicolumn{7}{|l|}{ GvHD } \\
\hline NCT02385019 & $\mathrm{I} / \mathrm{II}$ & 22 & $>18$ & Donor Tregs & $\begin{array}{l}0.5,1 \text { and } 2- \\
3 \times 10 \mathrm{e} 6 / \mathrm{kg}\end{array}$ & Unknown \\
\hline NCT03683498 & I & 16 & $\begin{array}{l}\text { Child, } \\
\text { adult and } \\
\text { older }\end{array}$ & Donor Tregs & $\begin{array}{l}0.5,1 \text { and } 2 \\
\times 10 \mathrm{e} 6 / \mathrm{kg}\end{array}$ & Recruiting \\
\hline NCT01795573 & $\mathrm{I}$ & 38 & $18-70$ & $\begin{array}{l}\text { Ex-vivo Expanded } \\
\text { Donor Regulatory } \\
\text { T Cells }\end{array}$ & NA & Active, not recruiting \\
\hline NCT02749084 & $\mathrm{I} / \mathrm{II}$ & 20 & $>18$ & $\begin{array}{l}\text { Multiple infusion of } \\
\text { Donor Tregs }\end{array}$ & $\begin{array}{l}0.5,1 \text { and } 2 \\
x 10 \mathrm{e} 6 / \mathrm{kg}\end{array}$ & Recruiting \\
\hline NCT01911039 & I & 20 & $>18$ & $\begin{array}{l}\text { Donor T } \\
\text { Regulatory Cells }\end{array}$ & $\begin{array}{l}0.1,0.5 \text { and } \\
1.5 \mathrm{x} \\
10 \mathrm{e} 6 / \mathrm{kg}\end{array}$ & Unknown \\
\hline \multicolumn{7}{|l|}{$\begin{array}{l}\text { Kidney } \\
\text { Transplant }\end{array}$} \\
\hline NCT02145325 & I & 10 & $18-65$ & $\begin{array}{l}\text { Autologous } \\
\text { polyclonally } \\
\text { expanded Tregs }\end{array}$ & $\begin{array}{l}0.5,1,5 x \\
10 e 9\end{array}$ & Active, not recruiting \\
\hline NCT02129881 & $\mathrm{I} / \mathrm{II}$ & 12 & $>18$ & $\begin{array}{l}\text { Autologous } \\
\text { polyclonally } \\
\text { expanded Tregs }\end{array}$ & $\begin{array}{l}1,3 \text { and } 6 x \\
10 \mathrm{e} 6 / \mathrm{Kg}\end{array}$ & Completed \\
\hline NCT02371434 & $\mathrm{I} / \mathrm{II}$ & 9 & $18-65$ & $\begin{array}{l}\text { Autologous } \\
\text { polyclonally } \\
\text { expanded Tregs }\end{array}$ & $\begin{array}{l}0.5,1,5 \mathrm{x} \\
10 \mathrm{e} 6 / \mathrm{Kg}\end{array}$ & Unknown \\
\hline NCT02244801 & $\mathrm{I} / \mathrm{II}$ & 16 & $18-70$ & $\begin{array}{l}\text { Donor alloantigen } \\
\text { reactive Tregs }\end{array}$ & $\begin{array}{l}3 \text { and } 9 x \\
10 e 8\end{array}$ & Completed \\
\hline NCT02091232 & $\mathrm{I} / \mathrm{II}$ & 8 & $>8$ & $\begin{array}{l}\text { Belatacept } \\
\text { conditioned Tregs }\end{array}$ & $\begin{array}{l}4 \text { and } 9 x \\
10 e 8\end{array}$ & Active, not recruiting \\
\hline NCT02088931 & I & 3 & $18-50$ & $\begin{array}{l}\text { Autologous } \\
\text { polyclonally } \\
\text { expanded Tregs }\end{array}$ & $3.2 \times 10 \mathrm{e} 8$ & Unknown \\
\hline NCT02711826 & I & 40 & $>18$ & $\begin{array}{l}\text { Donor alloantigen } \\
\text { reactive Tregs }\end{array}$ & $1 \times 10 \mathrm{e} 6 / \mathrm{Kg}$ & Recruiting \\
\hline ISRCTN11038572 & $\mathrm{Ilb}$ & 136 & $>18$ & $\begin{array}{l}\text { Autologous } \\
\text { polyclonally } \\
\text { expanded Tregs }\end{array}$ & $\begin{array}{l}5-10 \times \\
10 \mathrm{e} 6 / \mathrm{Kg}\end{array}$ & $\begin{array}{l}\text { Active, Not } \\
\text { recruiting }\end{array}$ \\
\hline NCT01446484 & I & 30 & $1-18$ & $\begin{array}{l}\text { Autologous } \\
\text { polyclonally } \\
\text { expanded Tregs }\end{array}$ & $2 \times 10 \mathrm{e} 8$ & Unknown \\
\hline
\end{tabular}




\begin{tabular}{|c|c|c|c|c|c|c|}
\hline NCT03284242 & $\mathrm{NA}$ & 12 & $18-65$ & $\begin{array}{l}\text { Autologous } \\
\text { polyclonally } \\
\text { expanded Tregs }\end{array}$ & $\mathrm{NA}$ & Not yet recruiting \\
\hline \multicolumn{7}{|l|}{$\begin{array}{l}\text { Liver } \\
\text { Transplant }\end{array}$} \\
\hline NCT02166177 & 1 & 9 & $18-70$ & $\begin{array}{l}\text { Autologous } \\
\text { polyclonally } \\
\text { expanded Tregs }\end{array}$ & $\begin{array}{l}0.5-1 \text { and 3- } \\
4.5 \mathrm{x} \\
10 \mathrm{e} 6 / \mathrm{Kg}\end{array}$ & Completed \\
\hline NCT02188719 & 1 & 24 & $21-70$ & $\begin{array}{l}\text { Donor alloantigen } \\
\text { reactive Tregs }\end{array}$ & $\begin{array}{l}0.5,2 \text { and } 8 \\
\times 10 \mathrm{e} 8 \\
\end{array}$ & Recruiting \\
\hline NCT02474199 & I & 18 & $18-70$ & $\begin{array}{l}\text { Donor alloantigen } \\
\text { reactive Tregs }\end{array}$ & $4 \times 10 \mathrm{e} 8$ & Recruiting \\
\hline NCT01624077 & 1 & 1 & $10-65$ & $\begin{array}{l}\text { Autologous } \\
\text { induced Tregs }\end{array}$ & $1 \times 10 \mathrm{e} 6 / \mathrm{Kg}$ & Unknown \\
\hline NCT03577431 & I/II & 9 & $17-70$ & $\begin{array}{l}\text { Belatacept } \\
\text { conditioned Tregs }\end{array}$ & $\begin{array}{l}2.5-500 x \\
10 \mathrm{e} 6\end{array}$ & Not yet recruiting \\
\hline
\end{tabular}

1082 UCB: Umbilical cord blood 